\title{
A SEGURANÇA AMBIENTAL E OS DILEMAS DA RECONSTRUÇÃO NOS PAÍSES EM DESENVOLVIMENTO ARRASADOS POR CATÁSTROFES NATURAIS E CONFLITOS: COOPERAÇÃO INTERNACIONAL OU CAPITALISMO DE DESASTRE?
}

\author{
Cláudio Tadeu Cardoso Fernandes ${ }^{1}$
}

\begin{abstract}
Many countries around the world have been stricken by large intensity natural phenomena whose consequences bring enormous human and material losses. Other countries have also started to suffer consequences of predatory environmental explorations and environmental transformations more intensely. Developing countries that have been through hard economic difficulties or situations of violent conflicts, apart from suffering with a large amount of deaths, poverty, and bad life conditions, have most of its infra-structure and production chains devastated. As a result, the need for reconstruction of these hard hit countries and the environmental issues have been important topics of discussion in international relations, with the rise of important concepts like sustainable development and global environmental security.
\end{abstract}

KEY-WORDS: global environmental security, international cooperation, natural catastrophes, conflicts.

\section{RESUMO}

Muitos países ao redor do mundo estão sujeitos a fenômenos naturais de grande intensidade, cujas consequiências trazem enormes perdas humanas e materiais. Outros países também começam a sofrer, de forma mais intensa, as conseqüências de explorações e transformações predatórias no meio ambiente. Países em desenvolvimento que passam por fortes dificuldades econômicas ou situações de conflitos violentos, além de sofrerem com a enorme perda de vidas, pobreza, e degradação das condições de vida, têm a maior parte de suas infra-estruturas e cadeias produtivas arrasadas. Assim, a necessidade de reconstrução de países arrasados e as temáticas ambientais têm sido importantes focos de discussão nas relações internacionais, tendo surgido importantes conceitos como desenvolvimento sustentável e segurança ambiental global.

PALAVRAS-CHAVE: Segurança Ambiental Global; Cooperação Internacional; Catástrofes Naturais; Conflitos;

\footnotetext{
* Mestre em Geografia pela Universidade de Brasília, Doutorando em Desenvolvimento Sustentável - Política e Gestão Ambiental no Centro de Desenvolvimento Sustentável - Universidade de Brasília. Professor do Curso de Geografia e do Curso de Relações Internacionais do Centro Universitário de Brasília.
} 


\section{A SEGURANÇA AMBIENTAL E OS DILEMAS DA RECONSTRUÇÃO NOS PAÍSES EM DESENVOLVIMENTO ARRASADOS POR CATÁSTROFES NATURAIS E CONFLITOS: COOPERAÇÃO INTERNACIONAL OU CAPITALISMO DE DESASTRE?}

Por sua localização geográfica, vastas regiões da Terra estão constantemente sujeitas a fenômenos naturais de grande intensidade, tais como ciclones, furacões, tornados, erupções vulcânicas, terremotos, secas, e inundações, cujas conseqüências na maioria das vezes trazem enormes perdas humanas e materiais. Além destas, um grande número de regiões antes consideradas como "privilegiadas pela natureza", começa a sofrer de forma mais intensa as consequiências de explorações e transformações predatórias no meio ambiente, como fenômenos ligados a mudanças climáticas aceleradas pelas ações antrópicas em escala global.

Regiões situadas em áreas próximas ao encontro de placas tectônicas estão sujeitas a violentos abalos sísmicos, que, quando ocorrem no fundo dos oceanos e mares, podem provocar ondas gigantes (tsunami), e afetar áreas litorâneas próximas ou distantes, como são os casos, por exemplo, da costa oeste da América do Norte, do Japão e do Sudeste Asiático. Muitas regiões também estão localizadas em áreas de ocorrência de violentos movimentos de massas de ar, resultantes das interações entre a atmosfera, os oceanos e os continentes, como ciclones, furacões, tempestades e tornados. Também os resultados de práticas humanas agressivas ao meio ambiente, tais como desmatamento, esgotamento dos solos, exploração excessiva de mananciais, e diversos tipos de poluição têm afetado principalmente os países situados em áreas sensíveis à exploração de recursos e crônica escassez de água, como é o caso, entre tantos outros, do avanço da desertificação na região do Sahel africano.

Seja devido a causas naturais ou antrópicas, um dos grandes desafios a ser enfrentado pelas populações e governos das regiões afetadas é como sobreviver a tais fenômenos, tendo em vista a sua intensificação. A situação torna-se ainda mais grave quando muitos países, além de sujeitos aos fenômenos mencionados, passam por dificuldades econômicas que geram pobreza e degradação nas condições de vida da maior parte de suas populações, e/ou situações de conflitos violentos, que ceifam um grande número de vidas humanas e arrasam a maior parte das infraestruturas e das cadeias produtivas.

\footnotetext{
* Mestre em Geografia pela Universidade de Brasília, Doutorando em Desenvolvimento Sustentável - Política e Gestão Ambiental no Centro de Desenvolvimento Sustentável - Universidade de Brasília. Professor do Curso de Geografia e do Curso de Relações Internacionais do Centro Universitário de Brasília.

Normalmente as situações de desastres naturais são bastante destacadas na mídia, provocando imediata sensibilização em sociedades de todos os continentes. As consequiências da temporada de furacões no hemisfério Norte em $2005^{1}$, e dos abalos sísmicos ocorridos no fundo do Oceano Índico e na Caxemira paquistanesa em dezembro de 2004, e outubro de 2005, respectivamente ${ }^{2}$, causaram grande comoção na comunidade internacional, em que mesmo governos e populações de países distantes mobilizaram-se para oferecer algum tipo de ajuda.

De acordo com o Human Development Report 2005,
}

"The year 2004 ended with na event that demonstrated the destructive power of nature and the regenerative power of human compassion. The tsunami that swept across the Indian Ocean left some 300,000 people dead. Millions more were left homless. Within days of the tsunami, one of the worst natural disasters in recent history had given rise to the world's greatest international relief effort, showing what can be achieved through global solidarity when the international community commits itself to a great endeavor ${ }^{3}$." 
Infelizmente, o mesmo nem sempre acontece com relação a outras situações, cujos prejuízos em termos de vidas humanas vêm também atingindo números inaceitáveis. Nesse sentido, o Human Development Report 2005 também faz uma significativa analogia:

"The tsunami was a highly visible, unpredictable and largely unpreventable tragedy. Other tragedies are less visible, monotonously predictable and readily preventable. Every hour more than 1,200 children die away from the glare of media attention. This is equivalent to three tsunamis a month, every month, hitting the world's most vulnerable citizens - its children. The causes of death will vary, but the overwhelming majority can be traced to a single pathology: poverty. Unlike the tsunami, that pathology is preventable. With today's technology, financial resources and accumulated knowledge, the world has the capacity to overcome extreme deprivation. Yet as an international community we allow poverty to destroy lives on a scale that dwarfs the impact of the tsunami ${ }^{4} . "$

${ }^{1}$ A estação de furacões no hemisfério Norte em 2005, em especial no Atlântico Norte, tem sido uma das mais intensas, tanto na quantidade como no poder de destruição destes fenômenos, causando enormes danos. O número de vítimas do furacão "Katrina", que atingiu a região de Nova Orleans, na costa norte-americana do Golfo do México, em agosto de 2005, é estimado em mais de mil pessoas, sendo considerado também o que causou maiores prejuízos econômicos desde 1820.

${ }^{2}$ O tsunami que devastou o Sul da Ásia, em dezembro de 2004, foi causado por um terremoto que atingiu 9 graus na escala Richter. O terremoto ocorrido em 08 de outubro de 2005, com epicentro na Caxemira Paquistanesa, atingiu 7,6 graus na escala Richter. Estima-se que tenha causado mais de 100.000 vítimas entre mortos e feridos.

${ }^{3}$ Human Development Report 2005, p. 1 .

${ }^{4}$ Idem.

Embora ainda seja bastante difícil mensurar todos os aspectos que se relacionam universalmente à qualidade de vida dos homens, os índices divulgados pela Organização das Nações Unidas, por meio do Human Development Report 2005 nos fornecem uma visão pouco otimista sobre a situação da maioria dos 177 países e territórios pesquisados. Grande parte desses paises e territórios não tem apresentado melhorias significativas na situação socioeconômica de parcelas consideráveis de suas populações. Ainda que vários deles tenham experimentado algum crescimento econômico, a concentração de renda e acumulação de riqueza por minorias em cada país parece ser um movimento em escala mundial. Dificuldades econômicas, conflitos armados, e a continuidade da situação de grande endividamento externo e transferência de recursos dos países pobres também é cada vez mais preocupante, gerando insustentabilidades institucionais e convulsões sociais, que remetem boa parte deles à situação de "nações inviáveis" ou "países falidos".

Em relação aos danos causados por conflitos armados, o Human Development Report 2005 constata que,

"Since 1990 more than 3 million people have died in armed conflict. Almost all of the deaths directly attributable to conflict have happened in developing countries. Apart from the immediate human costs, violent conflict disrupts whole societies and can roll back human development gains built up over generations. Conflict disrupts food systems, contributes to hunger and malnutrition and undermines progress in health and education. About 25 million people are currently 
internally displaced because of conflict or human rights violations. Nine of the 10 countries ranked at the bottom in the human development index have experienced violent conflict at some point since 1990 .",

Muitos analistas têm argumentado ultimamente que a maior parte dos conflitos armados no futuro próximo estará relacionada a problemas ambientais, como mudanças climáticas, o aumento do nível dos mares, e a escassez de água potável, gerando uma acirrada disputa por recursos e por territórios mais seguros. Assim, os países passariam a desenvolver poderosas armas para defender ou assegurar a posse de alimentos, água e estoques de energia, em que a estabilidade global estaria seriamente ameaçada. Por outro lado, a temática ambiental tem estado cada vez mais no centro das discussões entre os países, criando possibilidades para o diálogo e para a cooperação internacional.

${ }^{5}$ Human Development Report 2005, Chapter 5: Violent conflict - bringing the real threat into focus, p. 151.

Além de diversos tratados e acordos internacionais, as grandes conferências realizadas pela Organização das Nações Unidas, em Estocolmo (1972) e no Rio de Janeiro (1992), e a criação do Programa das Nações Unidas para o Meio Ambiente (PNUMA), podem ser considerados casos de sucesso ao fornecerem meios para o diálogo entre governos. A participação de cientistas, organizações não-governamentais e movimentos sociais, em especial na Conferência das Nações Unidas para o Meio Ambiente e Desenvolvimento, em 1992, também foi decisiva para a elaboração e a discussão de importantes conceitos e o estabelecimento de metas cujo alcance depende dos esforços de todos os povos.

Embora o conceito mais popularizado pela Conferência das Nações Unidas para o Meio Ambiente e Desenvolvimento tenha sido o "desenvolvimento sustentável", esta Conferência trouxe também à discussão o conceito de "segurança ambiental global", que se refere a estratégias de regulação do uso de recursos naturais com o emprego de técnicas de manejo ambiental, além do combate ao desperdício e à poluição. Para RIBEIRO (2002), os conceitos de segurança ambiental global e de desenvolvimento sustentável são centrais para o estabelecimento da ordem ambiental internacional, porém, em que pese o seu reconhecimento, estes conceitos

"envolvem a promoção de ajustes globais - nos quais os vários atores do sistema internacional certamente devem contribuir para que metas comuns sejam alcançadas - os países, principais interlocutores na ordem ambiental internacional, por meio de seus negociadores, têm procurado salvaguardar o interesse nacional. Agindo dessa forma, transformam as preocupações com a sustentabilidade do sistema econômico hegemônico e a possibilidade de que ele nos encaminhe para uma situação de risco em mera retórica 6."

$\mathrm{O}$ autor ainda argumenta que o conceito de segurança ambiental global requer a implementação de estratégias por uma unidade política e encontra mais resistências do que o conceito de desenvolvimento sustentável ${ }^{7}$. De fato, várias dimensões têm sido propostas para a operacionalização do conceito de desenvolvimento sustentável, como a ecológica, a ambiental, a econômica, a social, a política, a demográfica, a geográfica, a cultural, e a institucional, mas pouco tem sido abordado a respeito da segurança ambiental global. Todavia, os teóricos que 


\footnotetext{
${ }^{6}$ RIBEIRO, Wagner Costa. A ordem ambiental internacional, p. 109.

${ }^{7}$ Idem, p. 113.
}

têm trabalhado no aperfeiçoamento do conceito de desenvolvimento sustentável propõem a busca por uma sustentabilidade planetária, para onde convergiriam todas as dimensões, e envolveriam todas as questões que ultrapassam os Estados nacionais, dada a óbvia constatação de que os problemas ambientais não obedecem as fronteiras criadas pelos homens.

De qualquer forma, o aumento do consumo e as previsões de esgotamento das reservas de combustíveis fósseis, em especial o petróleo, antes do fim do século, vêm influenciando o quadro geopolítico mundial, cujas evidências parecem indicar que as principais potências econômicas e militares têm mobilizado enormes recursos para garantir o controle de importantes jazidas e áreas estratégicas de apoio à exploração e ao transporte, mesmo que isto signifique "ir à guerra". Apesar de toda a mobilização internacional no sentido da cooperação, novos dilemas também parecem influenciar de forma negativa a reconstrução dos países afetados por catástrofes naturais ou conflitos violentos.

Se após a Segunda Guerra Mundial foi estratégico para as potências vencedoras, principalmente os E.U.A., a reconstrução de vastas áreas atingidas pelo conflito, com destaque para os Planos Marshall e Colombo, voltados para a recuperação da Europa Ocidental e do Japão, atualmente começa a ganhar aceitação, entre muitos observadores, o conceito de "capitalismo de desastre".

A crise econômica de 1929 concorreu decisivamente para o acirramento de nacionalismos e tensões que levaram ao grande conflito entre 1939 e 1945 . Na emergência da Guerra Fria, o capitalismo encontrou equilíbrio numa adaptação do sistema fordista de produção e organização social, com uma espécie de "aliança" entre grandes corporações empresariais, o Estado, e as organizações de trabalhadores que, além de garantir uma relativa situação de "pleno emprego", ampliou os potenciais de consumo de grandes contingentes populacionais.

As sucessivas crises que têm abalado o sistema fordista em nível mundial a partir da década de 1970, como, por exemplo, os aumentos de preços do petróleo e o endividamento dos Estados, vêm provocando uma onda de reformas denominadas "neoliberais", associadas a práticas flexíveis nos espaços e nos processos de produção, bem como na contratação de mão de obra. Também o que atualmente se convenciona chamar de processo de globalização ou mundialização, apóia-se na erosão de poder e na capacidade de investimentos dos Estados, bem como é caracterizado pela intensa competição entre as empresas por mercados, gerando uma verdadeira "guerra entre os lugares" pela atração de investimentos.

Nesse sentido, até mesmo tragédias ocorridas em países em desenvolvimento parecem surgir como grandes oportunidades para os conglomerados empresariais de países ricos que atuam nos processos de reconstrução. As desconfianças tornaram-se mais latentes a partir da criação do Escritório de Coordenação para a Reconstrução e Estabilização pelo governo dos Estados Unidos, em agosto de 2004, cujas funções corresponderiam à elaboração de planos para países em situação de risco em todo o mundo.

No Afeganistão, das 22 Equipes de Reconstrução Provincial constituídas para estender o poder central às províncias, 13 são comandadas pelos Estados Unidos e 9 por outros países da OTAN. Apesar do empenho destas equipes no sentido de prestar assistência e garantir a segurança em remotas regiões do país, recente declaração do presidente Hamid Karzai sugere que seu governo "agora têm de lidar com uma praga de empreiteiros e construtores estrangeiros corruptos e insensatos ${ }^{8}$."

No processo de reconstrução do Iraque, estima-se que, somente a empresa norteamericana "Halliburton", especializada em logística e reparos em campos petrolíferos, tenha conseguido contratos em torno de US\$ 10 bilhões ${ }^{9}$. Segundo um relatório elaborado por organizações não-governamentais dos Estados Unidos e do Reino Unido, o Iraque está 
ameaçado por uma "nova onda colonial", podendo perder cerca de US\$ 200 bilhões caso entre em vigor, a partir de 2006, um plano de exploração de reservas petrolíferas por multinacionais norte-americanas e britânicas, reforçando a tese de que o verdadeiro objetivo da invasão em 2003 tenha sido o de garantir o controle sobre a $3^{\text {a }}$ maior reserva de petróleo do mundo ${ }^{10}$.

No Sri Lanka, o Movimento Nacional de Solidariedade aos Pescadores tem denunciado que o processo de reconstrução das regiões costeiras atingidas pelo tsunami tem priorizado a canalização de investimentos para a construção de hotéis de luxo e resorts, com a justificativa da geração de empregos, enquanto que mais de 90 mil sobreviventes pobres não tiveram sequer suas casas reconstruídas, habitando campos improvisados para refugiados ${ }^{11}$. Embora uma série de questões remeta o conceito de "capitalismo de desastre" a dúvidas, dada a complexidade e a variedade das situações de destruição e desestabilização, bem como das concessões dos governos às grandes empresas, sua discussão deve ser considerada pelas diversas organizações voltadas para a cooperação internacional. O conceito não deve também ser reduzido a perspectivas alarmistas de grupos de pressão, mas suas evidências devem ser profundamente investigadas. Assim, torna-se cada vez mais urgente a elaboração de mecanismos de controle sobre a aplicação dos recursos da ajuda e governança internacional, bem como da atuação de governos e grandes empresas nestes casos, como forma de garantir que os recursos possam beneficiar as populações mais afetadas.

${ }^{8}$ Conforme a Revista Carta Capital, 03 de agosto de 2005, p. 11

${ }^{9}$ Idem, p. 12.

${ }^{10}$ Conforme o Jornal Folha de S. Paulo, Caderno Mundo, 24/11/2005.

${ }^{11}$ Conforme a Revista Carta Capital, 03 de agosto de 2005, p. 08.

Finalmente, nas questões relacionadas à segurança ambiental global, e ao controle de recursos escassos, todos os esforços devem ser mobilizados no sentido de evitar e repudiar falsas justificativas realistas que busquem legitimar a guerra como "instrumento de política" no âmbito das relações internacionais.

\section{REFERÊNCIAS BIBLIOGRÁFICAS:}

BURSZTYN, Marcel. Ciência, ética e sustentabilidade. In: BURSZTYN, Marcel (org.). Ciência, ética e sustentabilidade. São Paulo: Cortez; Brasília: UNESCO, 2001, p. 09-20.

DUARTE, Lílian C. B. Política externa e meio ambiente. Rio de Janeiro: Jorge Zahar Editor, 2003.

FERNANDES, Cláudio Tadeu Cardoso. Desenvolvimento sustentável: afinal de contas, o que vem a ser isto? Breve histórico e referências conceituais. In: Universitas de Geografia, vol. 01, $\mathrm{n}^{\mathrm{o}}$ 01. Brasília: Uniceub, 2004, p. 89-103.

GOUDIE, Andrew. The Human Impact on the Natural Environment. Cambridge, Massachusetts: The MIT Press, 1991.

GRAÇA, Eduardo. O capitalismo de desastre. In: Revista Carta Capital: Política, Economia e Cultura. Ano XI, nº 353, 03 de agosto de 2005. São Paulo: Editora Confiança, p. 08-14.

MORAES, Márcio Senne de. OTAN admite ficar duas décadas no Afeganistão. In: Jornal Folha de S. Paulo, Caderno Mundo, 11 de setembro de 2005. 
RIBEIRO, Wagner Costa. A ordem ambiental internacional. São Paulo: Contexto, 2001.

SACHS, Ignacy. Caminhos para o desenvolvimento sustentável. Rio de Janeiro: Garamond, 2002.

SAND, Peter H. International Cooperation: The Environmental Experience. In: THE AMERICAN ASSEMBLY, Columbia University; WORLD RESOURCES INSTITUTE, Washington, D. C. Preserving the Global Environment: The Challenge of Shared Leadership. Jessica Tuchman Mathews Editor. New York, London: W. W. Norton \& Company, 1991, p. 236-279.

SANTOS, Boaventura de Sousa. Os processos de globalização. In: SANTOS, Boaventura de Sousa (org.). A globalização e as ciências sociais. São Paulo: Cortez, 2002, p. 25-102.

SANTOS, Milton. A Natureza do Espaço - Técnica e Tempo Razão e Emoção. São Paulo: Hucitec, 1997.

SOARES, Guido Fernando Silva. A interdependência dos Estados no campo da proteção internacional do meio ambiente. In: OLIVEIRA, Odete Maria de. JÚNIOR, Arno Dal Ri (orgs.). Relações internacionais: interdependência e sociedade global. Ijuí: Editora Unijuí, 2003, p. 599-627.

THORTON, Philip. Partilha do petróleo iraquiano está em curso, afirma relatório. In: Jornal Folha de S. Paulo, Caderno Mundo, 24 de novembro de 2005.

WALLERSTEIN, Immanuel. Após o Liberalismo: Em Busca da Reconstrução do Mundo. Petrópolis: Editora Vozes, 2002.

UNDP. Human Development Report 2005. 